\title{
A Design Approach of GSM, Bluetooth and Dual band Notched UWB Antenna
}

\author{
Durgesh Katre a, Prof. Rekha Labade ${ }^{\text {a }}$ \\ a Department of Electronics and Telecommunication, AVCOE, Sangamner-422608, India
}

\begin{abstract}
In this paper, printed GSM Bluetooth dual band notch UWB antenna is presented. In this prototype corner cut patch for Bluetooth application and dual band notch characteristics of UWB antenna perform by inverting USlot in the radiation patch of antenna. With the enclosing of $\lambda / 4$ stub in the patch of antenna for GSM (1.710$1.885 \mathrm{GHz}$ ) band operation. Simulation results show that the antenna yields an impedance bandwidth of 2.42.48 and 3-11 GHz with $-10 \mathrm{~dB}$ reflection coefficients, except for the dual notched bands of 3.3-3.7 for WiMAX and 5.15-5.825 GHz for WLAN. The electrical characteristics in frequency domain show suitability of this antenna for use in UWB systems.
\end{abstract}

Index Terms: GSM, Bluetooth, UWB, Dual band Notch.

(C) 2015 Published by MECS Publisher. Selection and/or peer review under responsibility of the Research Association of Modern Education and Computer Science

\section{Introduction}

Due to allocating unlicensed band from 3.1 to $10.6 \mathrm{GHz}$ by the Federal Communications Commission (FCC) for industrial and academic communities, ultra wideband (UWB) communication systems have get massive attention because of possessing significant advantages, such as high-speed data rate, high-precision ranging, , low complexity, low power consumption, simple hardware configuration and low cost [1]. Though, to design UWB antennas, there are some challenges including high radiation efficiency, the ultra-wideband performance in cost of the antenna size, constant gain etc. Antenna designs for UWB applications are facing many challenges including their impedance matching, electromagnetic interference (EMI) problems, radiation stability and especially the compact size design.

In the designated UWB operating band, several narrowband wireless standards have been allocated to share some parts of this spectrum. These include Worldwide Interoperability for Microwave Access (WiMAX) Service (3.3-3.7 GHz) and Wireless Local Area Network (WLAN) services IEEE802.11a (5.15-5.35 GHz and 5.725-5.825 GHz) [2], which might potentially interfere with the UWB systems. Hence, it is desirable for

* Corresponding author.

E-mail address: durgeshkatre19@gmail.com 
UWB antennas to perform the band-notched function to diminish the unwanted interferences from these coexisting wireless systems and remove the requirement of an additional band-stop filter. Among previously

Design of antenna there would be inserting several type of slot in the radiation patch or in the ground. A possible way to solve this problem is to design UWB antennas with band-notched characteristics Various techniques have already been proposed, such as using the embedded resonant cells [3], parasitic elements [4] and embedding U-shaped, L-shaped, V-shaped slots, or simple slits in planar antennas to introduce a frequency notch [5-7]. In [8] the dielectric resonator antenna (DRA) is proposed for UWB with U- strip and T-shaped slot in back plane embedded for the Dual band notch characteristics. Nowadays, GSM system has found wide application in mobile and portable wireless communications due to its great network capability and good stability [9].Various design of a novel approach to design an antenna for a transponder in radio frequency identification (RFID) is proposed. [13]

In this work, a novel compact micros trip-fed monopole antenna Design with GSM, Bluetooth and UWB applications is presented. By truncating radiation patch corner with circle, the Bluetooth and UWB are obtained. The rejection of WIMAX (3.3-3.7GHz) and WLAN $(5.15-5.825 \mathrm{GHz})$ is performed by the adding inverting Ushaped slot in the centre of the patch. The length of each slot has been taken about half of the guided wavelength at their respective notched band frequency. The position of each notched band can be controlled individually according to requirements of the system by changing the dimension or position of their respective slot.

\section{Antenna Design and Discussion}

\subsection{Structure of the Antenna}

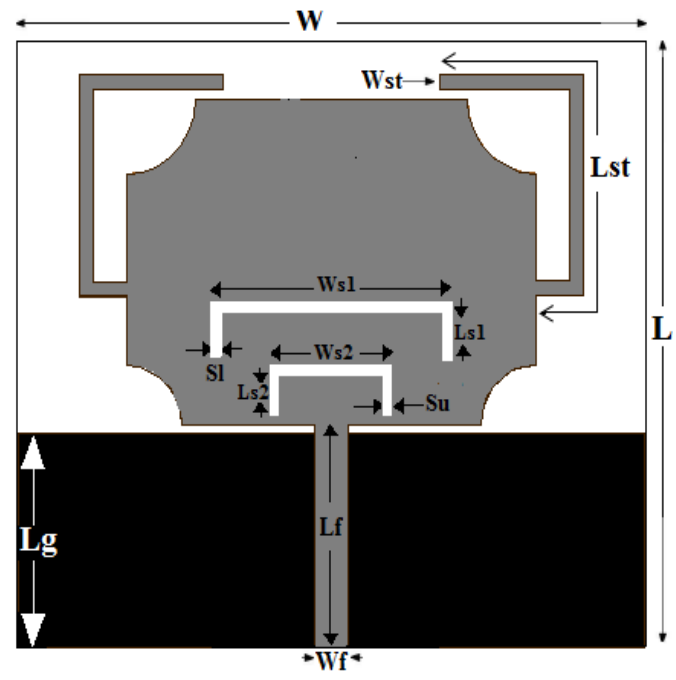

Fig.1. Geometry of Proposed Antenna

Fig. 1 shows the geometry of the proposed antenna. This antenna is built on a FR-4 substrate with a relative permittivity of $\varepsilon_{r}=4: 4$ and a loss tangent of 0.02 . The transverse dimension of this antenna is $48 \times 46 \mathrm{~mm}^{2}$. In designing, the patch antenna is used to cover the UWB range, which is the highest frequency band of the multiband antenna. Initially Bluetooth (2.4-2.48 GHz) and UWB (3.1-10.6 GHz) antenna is obtained by partial grounding technique (DGS) and a Dual notched band characteristic is performed on the UWB antenna without disturbing the Bluetooth and UWB antenna. After that for GSM band (1.710-1.885 GHz), the Quarter wavelength stub of centre frequency $1.797 \mathrm{GHz}$ is added to both side of the radiation patch of the antenna. 
Several aspects were considered to optimize the Final design like the overall impedance bandwidth of the antenna, the bandwidth of the notched bands, and the level of band rejection at notched frequency [10].

Table 1. Parameters of the Proposed Antenna.

\begin{tabular}{llllllllllllll}
\hline Parameter & W & L & Wp & Lp & Ws1 & Ws2 & Ls1 & Ls2 & S1 & Su & Lst & Wst & Lg \\
\hline Values/mm & 46 & 48 & 22 & 30.1 & 17.8 & 8.4 & 3.75 & 3.75 & 0.4 & 0.4 & 28.95 & 1 & 13.5 \\
\hline
\end{tabular}

\subsection{Antenna Performance}

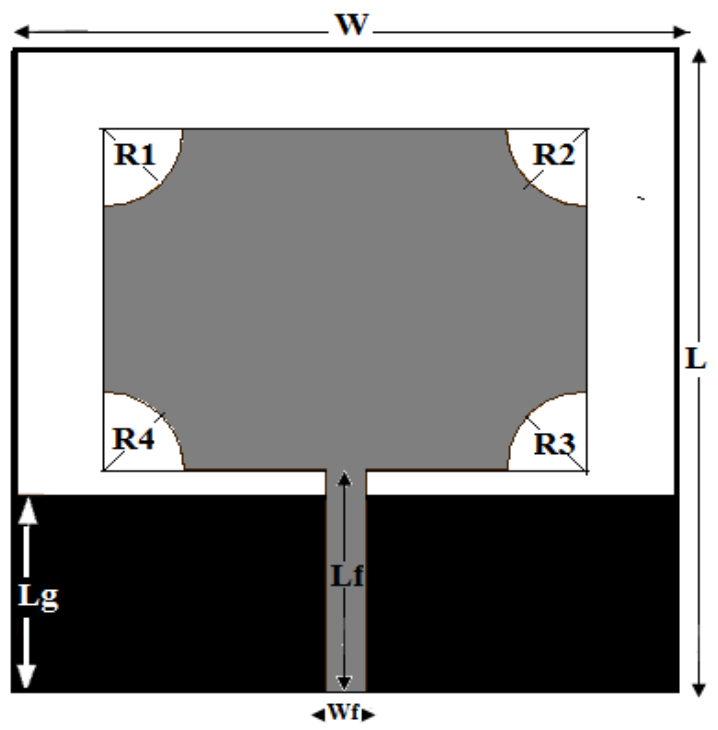

Fig.2. Shows Geometry of Bluetooth UWB antenna

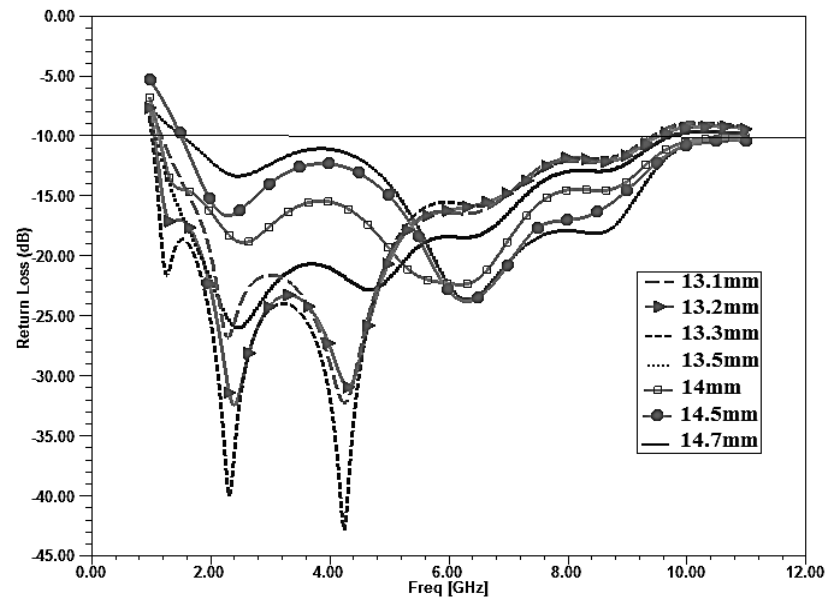

Fig.3. Show Parametric study of Ground (Lpg) 
An important feature of the proposed antenna is the capability of impedance matching of 1.5-10.6 GHz, except two frequency stop-bands by using the two slots which are presented. Fig. 2 shows the Bluetooth UWB antenna with the corner cut of $\mathrm{R} 1=\mathrm{R} 2=5 \mathrm{~mm} \& \mathrm{R} 3=\mathrm{R} 4=4 \mathrm{~mm}$. For impedance matching, effect of ground plane is more important.

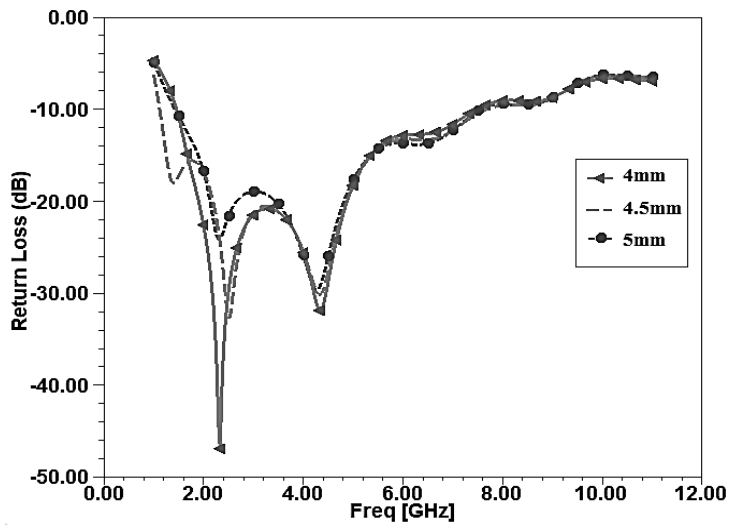

(a)

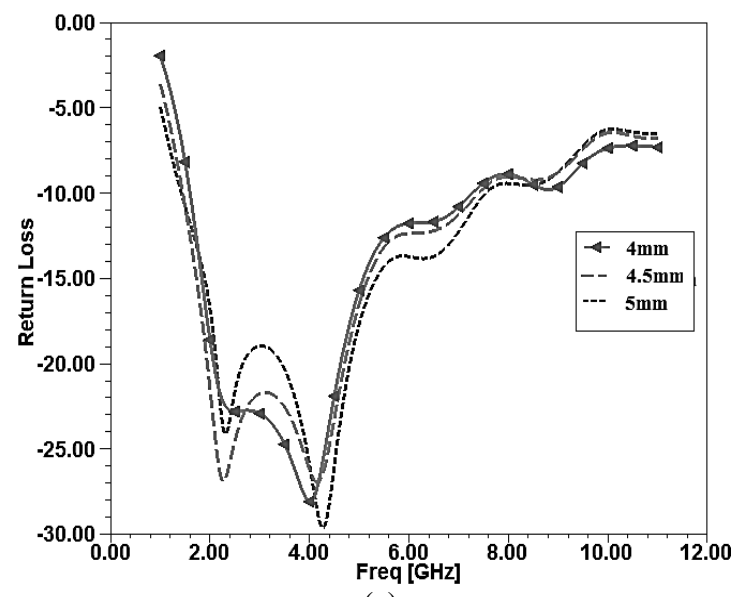

(c)

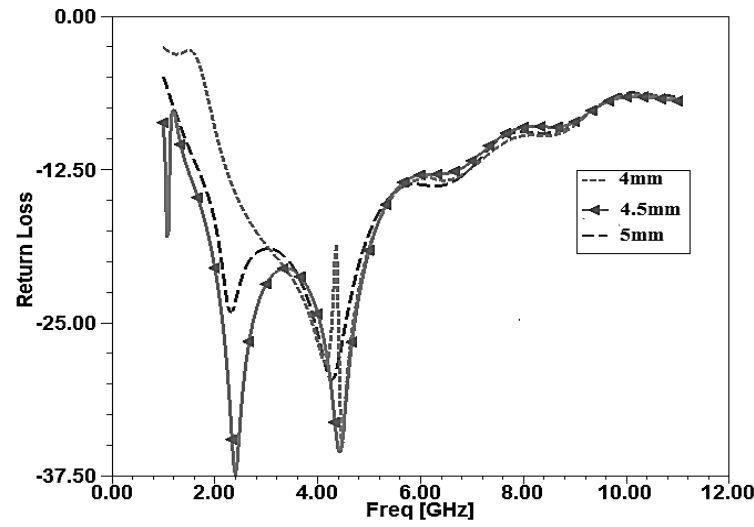

(b)

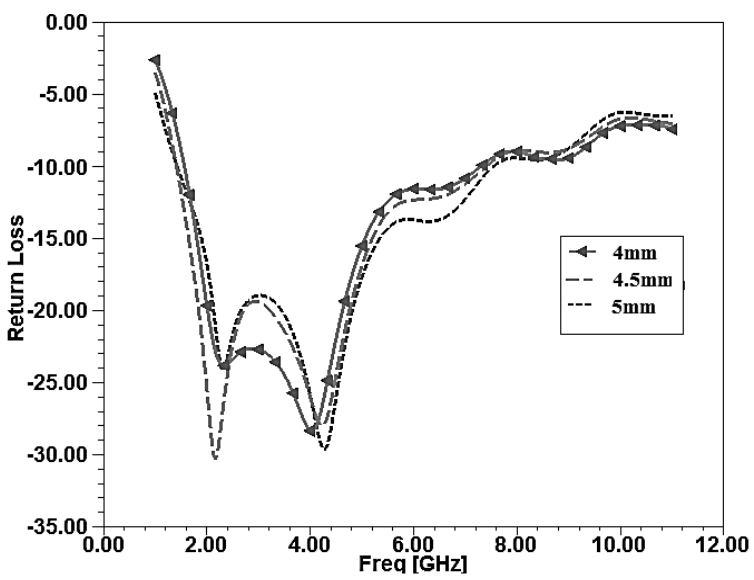

(d)

Fig.4. (a) Shows parametric Study of R1 (b) Shows parametric Study of R2 (c) Shows parametric Study of R3 (d) shows parametric Study of R4

As length of ground is increasing there is increasing the isolation but it will cause the Frequency resonance of antenna, while it should be constant at certain value shown in fig 3. For the Bluetooth operation of proposed antenna cut the corner of radius R1, R2, R3 \& R4. Parametric comparison of radii shown in fig 4. All the corner cut radiuses of antenna sustain their noble value for better impedance performance.

\subsection{Dual band Notched}

For dual band notch operation, inverted U-shaped slot has been cut on the patch of the antenna. Geometric parameters of the radiating patch and the ground plane affect characteristics of the impedance match. Due to the increasing demand for wireless connectivity, a single antenna to cover several allocates wireless frequency bands. 


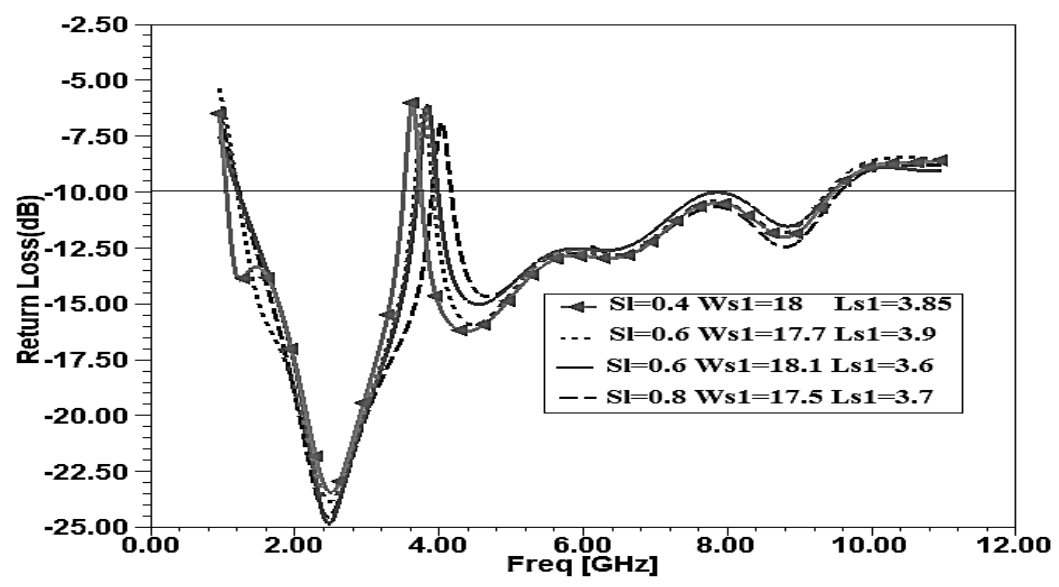

Fig.5. Shows Return Loss of Proposed Antenna with Slot of Centre Frequency 3.5GHz.

Due to interference of the dual band WIMAX (3.3-3.7 GHz) and WLAN (5.15-5.825GHz) is notched in the UWB. The length of slot is half of wavelength at centre frequency of the $3.3-3.7 \mathrm{GHz}$. The gap between the radiating patch and the ground plane affects impedance bandwidth because it acts as a matching network.

The length of the U-shaped slot can be calculated by,

$$
l i=\frac{c}{2 f_{i} \sqrt{\frac{\varepsilon_{r}+1}{2}}}
$$

The length of lower and upper slot is $L_{\text {lower }}=26.1 \mathrm{~mm} L_{\text {upper }}=19.6 \mathrm{~mm}$ for WIMAX and WLAN respectively. The U- shaped slot shown in fig 1 which is performing band notch function for WIMAX and WLAN. The effect of the width of Lower slot and upper slot shown in fig. 6 \& fig.7 correspondingly. In addition, at the desired frequency, only are the corresponding slots active while the others are inactive, approving the independence of the frequency bands. The natural elucidation is that the slots are not the major contributor of antenna performance [5]. The current distribution of the particular rejected band in proposed dual band notched antenna shown in fig.8.

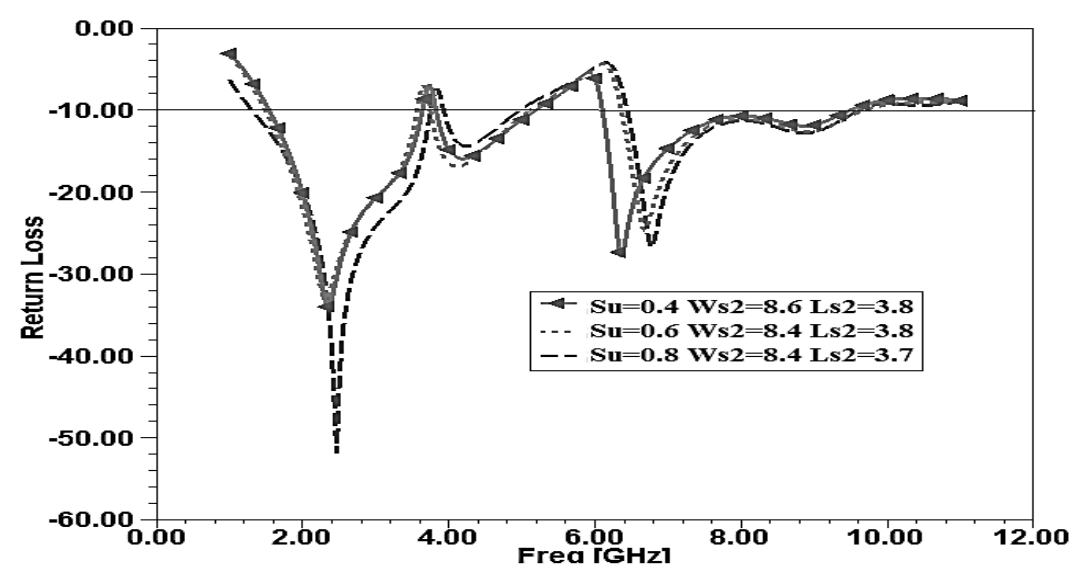

Fig.6. Shows Return Loss of Proposed Antenna with Slot of Centre Frequency 3.5 \& $5.5 \mathrm{GHz}$. 
Finally, half of wavelength stub of centre frequency $1.797 \mathrm{GHz}$ for GSM band to boost the particular frequency band. The stub dimensions are given in table no.1. In proposed band notch antenna the performance of the GSM operation of by optimising the length of stub shown in fig.1. The Simulated return loss of the proposed antenna shown in fig.7.

Fig. 8(a) and (b) shows the surface current concentrates along the $3.5 \mathrm{GHz}$ and $5.5 \mathrm{GHz}$ slot which acts as a capacitance of slot. If width of slot varies then the contrast in shunt capacitance of slot line occurs. The surface current along the slot differ with respect to slot width changes and bandwidth performance of proposed antenna is quiet change. The simulated surface current distribution on radiation patch has been stirred along the stub of the $1.797 \mathrm{GHz}$ which is shown in fig. 8(c).

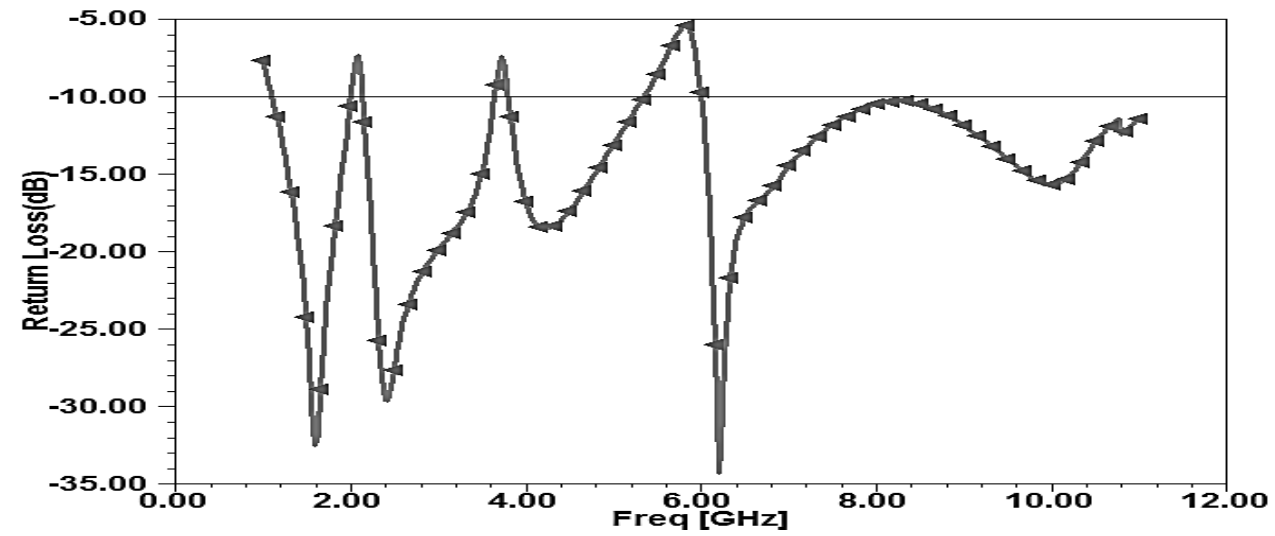

Fig.7. Shows the Simulated Return Loss of Proposed Antenna

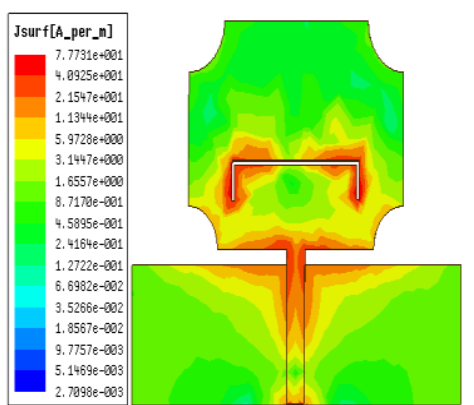

(a)

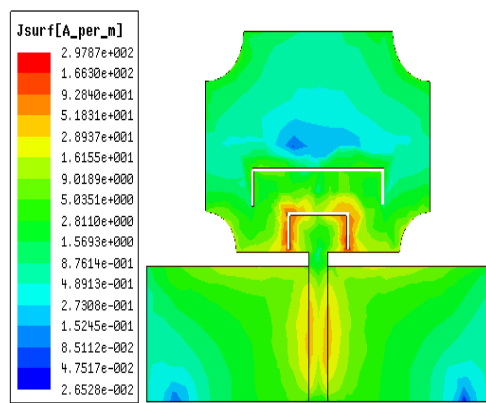

(b)

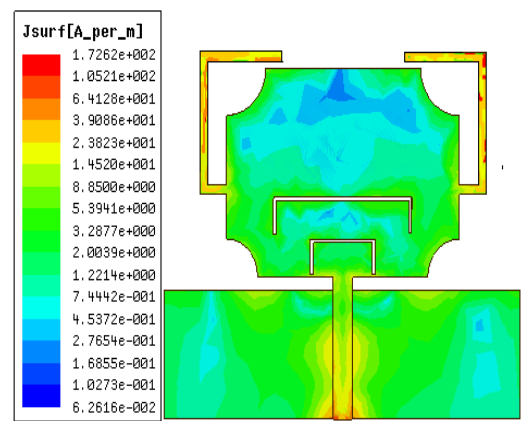

(c)

Fig.8. Surface Current Distribution on Antenna (a) with lower slot of $3.5 \mathrm{GHz}$ (b) With Upper slot of $5.5 \mathrm{GHz}$ (c) With the Stub of $1.7 \mathrm{GHz}$

\section{Results and Discussion}

In Fig. 9, it is can be seen that the proposed antenna has an impedance bandwidth of $1.5 \mathrm{GHz}$ to $10.6 \mathrm{GHz}$ for $S 11 \leq 10 \mathrm{~dB}$, except two frequency stop-bands of 3.3-3.7 GHz for Wi-MAX and 5.2-5.825 GHz for WLAN. The proposed GSM integrated, Bluetooth, dual band notched UWB antenna is simulated and shown in fig. Omnidirectional characteristics and radiation bandwidth can be improved if the ground plane length is approximately the same size as that of the radiating structure width [11] and by using a thin substrate or a substrate with low dielectric constant [12]. The proposed antenna has nearly omnidirectional radiation characteristic in the $H$ plane and a fig. of eight radiation pattern in the $E$ plane over the desired band. The proposed antenna provides more than $85 \%$ radiation efficiency except at the notched frequency bands as shown 
in Fig. 13. The gain varies between $2 \mathrm{~dB}$ and $5 \mathrm{~dB}$ over the 1.5-10.6 GHz frequency range except in the 3.3-3.7 $\mathrm{GHz}$ and 5.2.-5.825 GHz notched frequency bands.

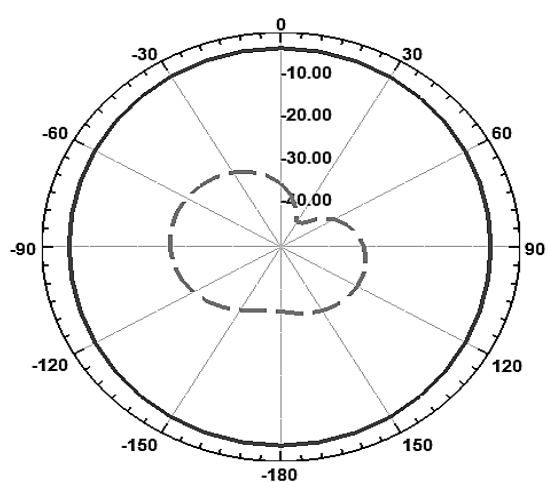

(a) $1.7 \mathrm{GHz}$

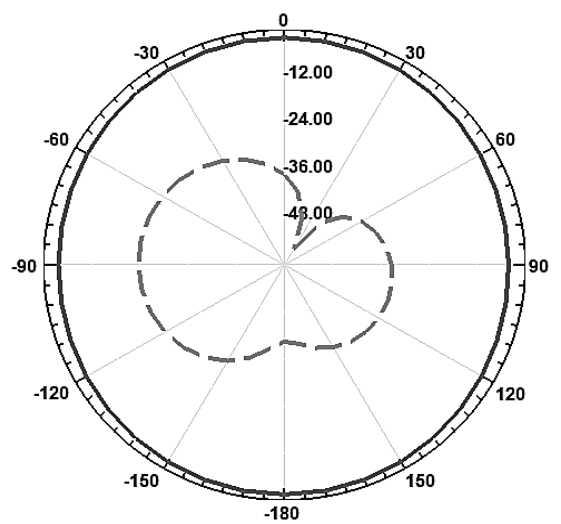

(c) $2.4 \mathrm{GHz}$

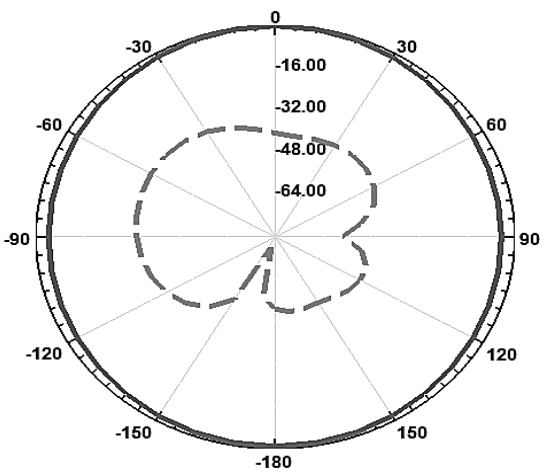

(e) $4.2 \mathrm{GHz}$

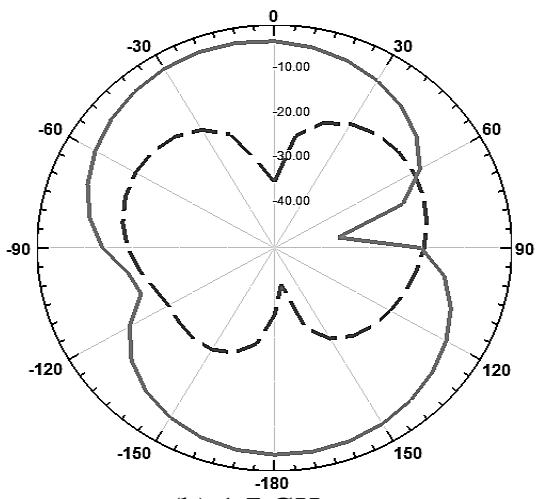

(b) $1.7 \mathrm{GHz}$

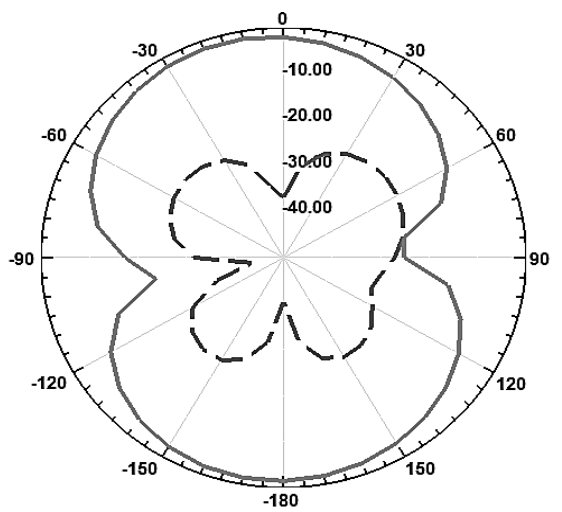

(d) $2.4 \mathrm{GHz}$

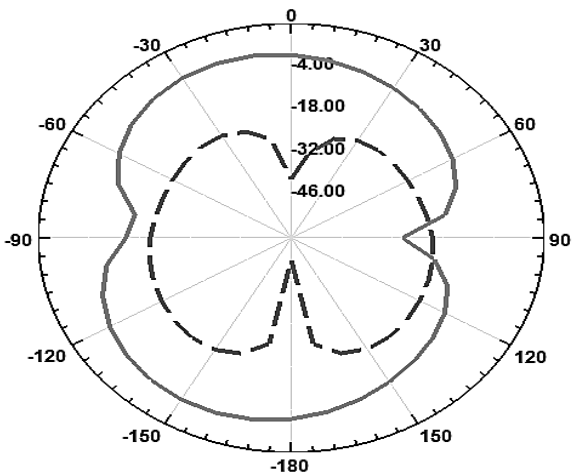

(f) $4.2 \mathrm{GHz}$

Co-Polar

Cross-Polar

Fig.9. Simulated Radiation Pattern For proposed Antenna (a) (c) (e) H-plane and (b), (d), (f) E-plane 


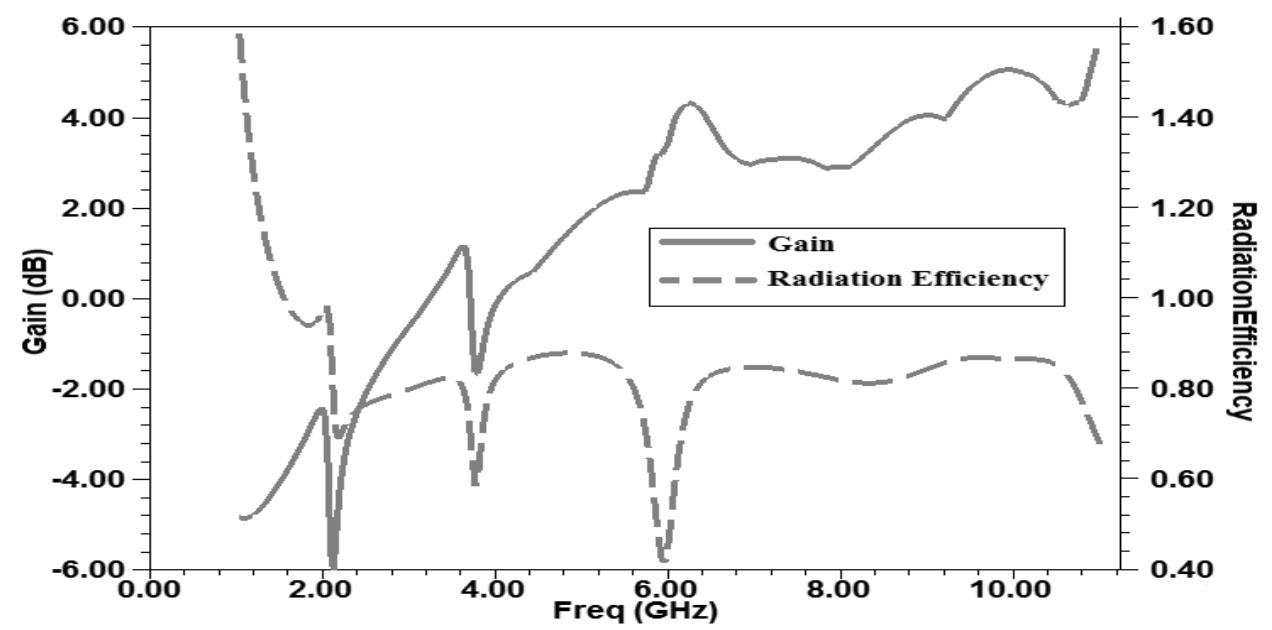

Fig.10. Simulated Gain and Radiation Efficiency of Proposed Antenna.

\section{Conclusion}

The characteristics novel approach of GSM, Bluetooth, UWB antenna with the rejection of the Wi-LAN and Wi-MAX is presented and verified with simulation result. By parametric study, to find the optimal dimension of the Stub and resonating structure of antenna. With amendment of inverted U-Shaped slot rejection in WiLAN and Wi-MAX is obtained.

\section{References}

[1] Federal Communications Commission Revision of Part 15 of The Commission's Rules Regarding Ultra Wideband Transmission System From 3.1 To 10.6 GHz, Federal Communications Commission, FCC, ET-Docket, 98-153, Washington, DC, 2002.

[2] C. C. Lin, P. Jin, And R. W. Ziolkowski, "Single, Dual And Tri-Band notched Ultra wideband Antennas Using Capacitively Loaded Loop Resonators," IEEE Trans. Antennas Propag., Vol. 60, No. 1, Pp. 102109, Jan. 2012.

[3] Jang, J.-W. And H.-Y. Hwang, "An Improved Band-Rejection UWB Antenna with Resonant Patches and A Slot," IEEE Antenna and Wireless Propagation Letters, Vol. 8, 299-302, 2009.

[4] Viet Hoang-The, Quyet Nguyen-Manh, Dong Hyun Lee, And Hyun Chang Park "Integrated Bluetooth/IMT-E And UWB Planar Antenna Using SCRLH Resonator To Reject WLAN And Wi-MAX Interferences," Progress In Electromagnetics Research C, Vol. 42, 39-53, 2013.

[5] S-M. Zhang, F.-S. Zhang, W.-Z. Li, T. Quan, and H.-Y. Wu "A Compact UWB Monopole Antenna with Wi-MAX and WLAN Band Rejections," Progress In Electromagnetics Research Letters, Vol. 31, 159$168,2012$.

[6] S. K. Mishra* And J. Mukherjee "Compact Printed Dual Band-Notched U-Shape UWB Antenna," Progress In Electromagnetics Research C, Vol. 27, 169-181, 2012.

[7] Z.-M. Yan, Y.-S. Xu and W.-D. Wang "Miniaturized Ultra wideband Wide Slot Antenna with Dual BandNotches and Eliminating Spurious Stop Band," Progress in Electromagnetics Research C, Vol. 30, 119130, 2012.

[8] M. Abedian, S. K. A. Rahim, Sh. Danesh, S. Hakimi, L. Y. Cheong, And M. H. Jamaluddin "Novel Design Of Compact UWB Dielectric Resonator Antenna With Dual-Band-Rejection Characteristics For Wi-MAX/WLAN Bands ," IEEE Antennas And Wireless Propagation Letters, Vol. 14, 2015245. 
[9] Guihong Li, Huiqing Zhai, Tong Li, Xiaoyan Ma, And Changhong Liang "Design of A Compact UWB Antenna Integrated With GSM/WCDMA/WLAN Bands," Progress In Electromagnetics Research, Vol. 136, 409-419, 2013.

[10] Sai K. Venkata, Muktikanta Rana, Pritam S, "Planar Ultra wideband Monopole Antenna With Tri-Notch Band Characteristics," Progress In Electromagnetics Research C, Vol. 46, 163-170, 2014.

[11] Wu, Q., R. Jin, J. Geng, and M. Ding, "Printed Omni-Directional UWB Monopole Antenna with Very Compact Size," IEEE Trans.Antennas Propagation, Vol. 56, 896-899, 2008.

[12] Mishra, S. K., R. K. Gupta, and J. Mukherjee, "Effect of Substrate Material on Radiation Characteristics of an UWB Antenna," IEEE Loughborough Antennas \& Propagation Conference, LAPC, 157-160, UK, 2010.

[13] Omrane NECIBI, Abdelhak FERCHICHI Tan-phu VUONG, Ali GHARSALLAH "A Discussion of a $60 \mathrm{GHz}$ Meander Slot Antenna for an RFID TAG with Lumped Element" I.J. Wireless and Microwave Technologies, 2014, 2, 1-11.

\section{Author(s) Profiles}

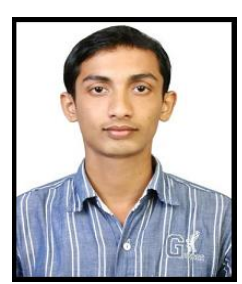

Durgesh D. Katre has completed BE from Nagpur University. He is pursuing ME in Microwave Engineering from Amrutvahini College of Engineering, Pune University.

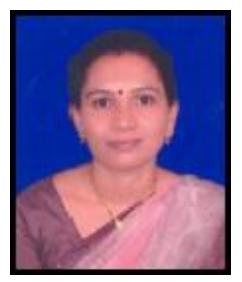

Prof. R.P Labade has completed ME in Electronics from JNEC, Aurangabad. She is working as a Head of department of Electronics \&Telecommunication in Amrutvahini college of Engineering sangamner. Her area of interest is Microwave communication and antenna design. She is currently pursuing her PHD in field of microwave communication.

How to cite this paper: Durgesh Katre, Rekha Labade,"A Design Approach of GSM, Bluetooth and Dual band Notched UWB Antenna", IJWMT, vol.5, no.6, pp.35-43, 2015.DOI: 10.5815/ijwmt.2015.06.05 